\title{
El ejército cristiano en la España altomedieval: de la derrota militar ante los musulmanes, a la resistencia espontánea frente a ellos
}

\author{
The Christian Army in Early Medieval Spain: From Military Defeat by \\ the Muslims to Spontaneous Resistance to them
}

\author{
Ma Isabel PÉrez de Tudela Velasco \\ Universidad Complutense. Madrid \\ pertucas@ghis.ucm.es
}

\begin{abstract}
RESUMEN
El presente trabajo trata de analizar las causas, internas y externas del fracaso bélico cristiano ante la invasión musulmana, a la luz de los testimonios cronísticos más tempranos. Y, a partir de las mismas fuentes, ahondar en el proceso de reconstrucción material y moral que, protagonizado por ciertos grupos, fructificó en los llamados núcleos de resistencia cristianos. Así como valorar, en este contexto, el papel que correspondió a una reorganización de signo militar.
\end{abstract}

Palabras clave: Ejército visigodo. Los vitizanos. La conquista islámica. Los pactos. Don Pelayo

\begin{abstract}
The present study attempts to analyze the internal and external causes of the Christian military failure facing the Islamic invasion in the light of the earliest chronicled testimonies. Based on the same sources, it also delves into the process of moral and material reconstruction led by certain groups that flourished in the socalled nuclei of Christian resistance. In this context, it also aims to evaluate the role of reorganization along military lines.
\end{abstract}

Keywords: Visigoth military. Supporters of King Witiza. Islamic conquest. Pacts. Pelayo

Sumario: La derrota del ejército visigodo y sus causas. La derrota del ejército visigodo: las consecuencias. La recuperación de la conciencia de identidad y sus soportes 
En el verano del año 711, se cumplen ahora trece siglos, un ejército procedente de África integrado por musulmanes y cristianos derrotó en el campo de batalla a las tropas fieles al rey visigodo Rodrigo. El rey, desaparecido en el curso de los combates, se convirtió en el último de los godos y el reino que él señoreaba, ambicionado por unos y traicionado por otros, desapareció asimismo del escenario histórico. A partir de estas premisas se entiende que el año de referencia y los acontecimientos que en él se vivieron se convirtiera en uno de los más trascendentales de la Historia de España. Cronistas e historiados se han ocupado, desde entonces, de sondear los arcanos de aquellos tiempos en busca de sus claves interpretativas. Se trataba $-\mathrm{y}$ trata, también ahora- de una operación que al tener, considerable carga ideológica pronto suscitó fuertes controversias. Controversias relativas fundamentalmente al sentido de los acontecimientos y a la valoración de sus consecuencias. Controversias alimentadas, desde luego, por la escasez de las fuentes tempranas y la fuerte carga ideológica de que están dotadas las que corresponden a los periodos siguientes.

Todo ello determina la exigencia de un análisis en tiempo largo que, sorteando las lagunas informativas y sobrevolando barreras ideológicas, trate de encontrar la línea argumental de un proceso cuya coherencia interna parece escapársenos tal vez porque se nos escapen igualmente los tiempos y las pulsaciones de su andadura.

Pues bien, de entre todas las instituciones que han merecido la atención de las susodichas fuentes tempranas, sin duda la militar -el ejército, específicamente- es la más significativa.

La Crónica mozárabe del $754^{1}$ es la primera en ofrecer una versión de los dramáticos acontecimientos que se sucedieron tras el desembarco de los musulmanes en la Península Ibérica. Se trata de un relato en extremo abreviado que tiene su eje argumental en la conducta y el destino del rey Rodrigo ${ }^{2}$. Un personaje que, según esta fuente, no reinó más que un año, al cabo del cual debió convocar un ejército para contener las incursiones que, protagonizadas por árabes y moros, estaban devastando, desde tiempo atrás, provincias y ciudades de su reino y que pereció al enfrentarse a ellos. Ahora bien; la brevedad del relato no es óbice para que su autor, inserte un apunte sobre las causas de la derrota. Para él, la muerte de Rodrigo y la dispersión de los combatientes visigodos se debieron a la desafección del ejército que le había acompañado con engaños, de forma fraudulenta, porque en realidad lo que ambicionaba era el reino sobre el que él señoreaba. En otros términos; fue la deserción de parte del ejército visigodo la causa inmediata del desastre. No obstante lo anterior, conviene hacer notar que el cronista tampoco exculpa a Rodrigo. En efecto, el párrafo que comentamos da comienzo con una frase ambigua en la que el cronista acusa

${ }^{1}$ Sobre esta fuente véase R. Collins, La conquista árabe, 710-797, Historia de España, III Barcelona, 1991, p. 31 y Th. Deswarte, De la destruction à la $r$ estauration. L'idéologie du r oyaume d'Oviedo-Leon (VIIIe-XIe siècles), Turnhout, 2003, pp. 40 y ss.

2 "(Rudericus) regnat anno uno. Nam adgregata copia exercitus aduersus Arabas una cum Mauros a Muze missos, id est Taric abuzara et ceteros, diu sibi prouinciam creditam incursantibus simulque plerasque ciuitates deuastantibus, anno imperii Iustiniani quinto, Arabum nonagésimo tertio, Ulit sexto, in era DCCL transductinis promontoriis sese cum eis confligendo recepit eoque prelio fugatum omnen Gothorum exercitum, qui cum eo emulanter fraudulenterque ob ambitionem regni aduenerant, cecidit." Crónica Mozárabe de 754, ed. J. E. López Pereira, Zaragoza, 1980, c. 52 
a Rodrigo de haber invadido el reino "tumultuosamente", aun cuando contara con el apoyo del senado ${ }^{3}$. En resumen; la "invasión" del reino por parte de Rodrigo sería la causa última ${ }^{4}$ y la deserción de sus contrarios, la causa inmediata, del sesgo histórico ocurrido el 711.

En este contexto no tiene nada de particular que el párrafo de referencia termine con una frase tan lacónica como expresiva en la que el anónimo cronista vuelve a recordar la muerte del rey, pero consignando que también sus "émulos" perecierons, por lo que ignominiosamente se perdió "regnum simulque cum patriam". Esto es; fue el mal hacer de unos y otros el responsable del ocaso del reino visigodo y de la ruina de la patria común.

Pero de todo lo anterior también se desprende que fue la huida del ejército visigodo el desencadenante de la serie de desgracias que culminaron en la "pérdida de la patria". Podemos expresarlo también, en la terminología de la Crónica: fue la destrucción del ejército visigodo lo que propició el triunfo del ejército de Muza y la consiguiente conversión del "regnum Gothorum" en tributario del "Sarracenorum".

Una visión de los acontecimientos de los años 711 y 712 que las crónicas asturianas recordaron, siglos después, de forma sintética en frases tales como: "Y como el rey hubiera sabido de su entrada (la de los musulmanes), al momento salió con el ejército para luchar contra ellos. Puesto en fuga el ejército fue destruido hasta casi el exterminio"6.

Pues bien si en la destrucción del ejército godo vieron los cronistas cristianos de fines del siglo Ix y comienzos del x las claves de la "pérdida" de España, en su reconstrucción depositaron las esperanzas de una pronta restauración 7 . Y ese fue el cometido que correspondió, según ellos, a Pelayo, a los duques de Cantabria y a sus sucesores.

\section{LA DERROTA DEL EJÉRCITO VISIGODO: SUS CAUSAS}

Ya hemos visto como la gran fuente cristiana de la primera hora, la Crónica mozárabe del 754, había ofrecido una versión algo ambigua de los hechos pero, en cualquier caso, interpretada en clave de agresión externa confabulada con deserciones interiores. Pues fue, en última instancia, la traición de buena parte del ejército visigodo, la causa de la fuga generalizada y de la muerte del rey Rodrigo: “...eoque proelio fugatum omnem eorum exercitum, qui cum eo emulanter fraudulenterque ob

3 "Rudericus tumultuose regnum ortante senatu inuadit", Crónica Mozárabe de 754, c. 52.

${ }^{4}$ A favor de la legitimidad de Rodrigo se inclinan historiadores de la talla de: Sánchez Albornoz, Orlandis, Barbero y Vigil, así como García Moreno. Contrarios a la aceptación de los derechos del último rey visigodo son Thompson y Collins. Véase el resumen que sobre las mencionadas posiciones hace C. de Ayala Martínez, Sacerdocio y reino en la España altomedieval, Madrid, 2008, pp. 93 y ss.

${ }^{5}$ R. Collins (La conquista árabe, p. 33) partiendo de una interpretación personal del relato de la crónica mozárabe, admite la destrucción de las fuerzas visigodas en las fechas próximas a la batalla, apuntando incluso como hipótesis que el debilitamiento del ejército visigodo pudiera deberse a "un ataque preventivo" lanzado por don Rodrigo contra sus opositores.

${ }^{6}$ Crónica Rotense, 7: "Quumque rex ingressum eorum cognouisset, statim cum exercitu egressus est eis ad uellum... Quo exercitus fugatus usque ad internicionem eo pene est deletus."

7 Sobre estas fuentes véase A. Besga Marroquín, orienes hispano-godos del r eino de Asturias. Oviedo, 2000, pp. 38 y ss. 
ambitionem regni aduenerant, cecidit"s. También según su autor, las consecuencias no pudieron ser más nefastas porque de resultas del hecho militar se perdió todo. Y digo todo, porque en frase lapidaria nuestro cronista responsabiliza -al rey y a sus rivales, también muertos-, de haber dejado escapar "el reino, juntamente con la patria". Se trata, evidentemente de una acusación de hondo calado, con todos los rasgos de una sentencia en firme: Rodrigo, el usufructuario de la corona, y sus émulos, compitiendo por el "reino" de los godos, habían logrado perderlo para todos.

Esa fue la lectura que de este texto hicieron los cristianos peninsulares de los siglos inmediatamente posteriores a la entrada de los musulmanes. Digo esto porque dentro de esa línea argumental se moverá toda la primera cronística cristiana y, en concreto, la del período astur. Sus autores serán los que consagren una versión de aquellos acontecimientos cuya gravedad vino determinada por la combinación de una agresión externa, sumada a la fragmentación interna. Y ellos mismos fueron los que al poner el dedo acusador en el segundo factor, lo conviertan en causa determinante del colapso del reino visigodo. Veámoslo con algún detenimiento.

En este sentido se manifiesta una fuente tan sucinta en cuanto a las noticias y tan parca en reflexiones como es la Crónica Albeldense. Su autor, tras afirmar que Rodrigo reinó tres años, añade que en su tiempo, en la era 752, "llamados por los enredos del país, los sarracenos ocupan España y se apoderan del reino de los godos, que todavía retienen en parte de manera pertinaz"10. En su esquematismo, la frase es, sin duda, expresión clara de la imagen que la memoria colectiva de los cristianos del norte peninsular conservaba de aquel acontecimiento trascendental para ellos: las intrigas de los godos propiciaron el apoderamiento de España por parte de los musulmanes.

Pero hay más, las graves acusaciones dirigidas por el autor de la Crónica mozárabe contra los partidos que se disputaban el poder el año de la invasión, no pasaron desapercibidas en los círculos intelectuales cristianos a juzgar por el hecho de que siglos después, el autor de la crónica "a Sebastián" recogiera, casi a la letra, el sentimiento de hondo pesar y pérdida irreparable que desprendía la frase de su colega del siglo vIII. Bien sea porque compartiera estas mismas emociones, bien porque participara del juicio histórico emitido por su antecesor, o por ambas razones a la vez, lo cierto es que resumió las consecuencias del desastre militar en una frase contundente: "Arabes tamen patria simul cum regno oppresso pluribus annis per presides Babilonico regi tributa persoluerunt" ". Es cierto que el anónimo compilador de esta

${ }^{8}$ Crónica mozárabe, 52, p. 68.

${ }^{9}$ Entiendo que la frase "Sicque regnum simulque cum patriam male cum emulorum internicione amisit" puede ser traducida de la siguiente forma: "Y así, por desgracia, dejó escapar al tiempo, reino y patria, con la muerte de sus émulos.” (Crónica Mozárabe de 754, 52, p. 68).

10 "Rudericus... Istius tempore era DLLII farmalio terre Sarraceni euocati Spanias occupant regnum Gotorum capiunt, quem aduc usque ex parte pertinanciter possedunt. Añadiendo: Et cum eis Chrispiani die noctuque bella iniunt et cotidie confligunt" ("Y con ellos los cristianos día y noche afrontan la batalla y cotidianamente luchan pero no logran quitarles España del todo".), (XIV, 34).

11 "Los árabes, dominada la patria junto con el reino, durante varios años pagaron tributo al rey de Babilonia...<ad Sebastianum>, 8, p. 123. La versión rótense $(8$, pp. 122) aún utilizando recursos literarios propios, mantiene el sentir de su predecesor: "Araues tamen regionem simul et regno opresso plures gladio interfecerunt". 
versión de la crónica Alfonsina, ha condensado en poco más de una línea las dos ideas básicas del autor mozárabe: los árabes dominaron España y la convirtieron en tributaria del reino babilónico; pero hay más, porque al prescindir de Rodrigo como sujeto de referencia, convierte los vocablos "patria" et "regno" en conceptos absolutos, alusivo el primero a la España cristiana y el segundo al sistema de gobierno y poder impuesto por los godos sobre el susodicho territorio.

En este punto tendríamos que preguntarnos acerca de las razones que movieron al cronista asturiano a entroncar su escrito en la línea argumental y sentimental propia de los tiempos de la conquista, renunciando a una elaboración propia, como inmediatamente, veremos que hizo el autor de la rótense. Podemos pensar que lo hiciera porque compartía las percepciones del susodicho historiador pero, mejor aún, porque encontrara en la frase las urdimbres necesarias para elaborar ese concepto legitimador de la resistencia armada a los musulmanes que es el de la "pérdida de España".

En efecto; conviene advertir que la versión rótense de la Crónica de Alfonso III utilizó recursos estilísticos propios para relatar los mismos sucesos: "Araues tamen regionem simul et regno oppreso..."'2. Unos recursos que aún cuando se limitaran, esencialmente, a la sustitución del vocablo "patria" por el de "regiones" adquieren en este contexto una gran significación. Porque lo que se perdió tras la derrota ya no fue la patria, sino las regiones -la tierra, pudiéramos leer nosotros-, así que los cristianos estaban llamados a recuperar no es tanto la "patria goda", como las tierras de Hispania.

No obstante; como los autores de una y otra fuente recurrieron a la misma expresión condensada para referirse al triunfo del proyecto conquistador -"los árabes, dominada la tierra (o la patria en su caso) junto con el reino..."- queda claro para ellos la pérdida de la tierra y del reino era el binomio sobre el que se había forjado, de una parte el ocaso del reino visigodo y de otra el alborear de la etapa islámica.

Pues bien; de este tenor son todos los tratamientos que las fuentes posteriores han hecho de episodio tan trascendenta ${ }^{13}$.Y es que, como ya dije más arriba, toda la historiografía hispana posterior interpretó aquella derrota en clave de guerra civil - un episodio más de tantos cuantos vivió la España visigoda- sumada a agresión externa -esto es, invasión-. Así lo hicieron las crónicas del período astur, sólo que ellas empezarán a poner nombre a los traidores y etiquetas a sus responsabilidades sociales. A la par que marcaban tiempos a su colaboración con el invasor.

Pero volvamos a las cuestiones relativas a las disensiones visigodas. Tal vez la fuente más locuaz y comunicativa al respecto sea la crónica rótense. Su autor sintetizó el gobierno del rey Rodrigo, con estas palabras: "en el año tercero de su reinado, y a causa de la traición de los hijos de Vitiza, entraron los sarracenos en España", para añadir en líneas posteriores una referencia concreta al destino que esperaba a los combatientes cristianos en la batalla del Guadalete por causa de la alevosía de algunos de ellos: "traicionados por el fraude de los hijos de Vitiza, fueron puestos en

${ }^{12}$ Rotense, 8.También encontramos esta fórmula en Crónica Albeldense, XVII, $3^{a}$ : Arabes tamen regiones simul cum regno possessam...

${ }^{13}$ A modo de ejemplo apuntar que a Julián y a los hijos de Witiza atribuye Lucas de Tuy el desastroso fin de los godos libro III, caps. LXIV, LXV. 
fuga" ${ }^{4}$. Es cierto que las reiteradas denuncias de la doblez de los vitizanos, pueden ser leídas tanto en clave histórica, como didáctica y ejemplarizante, pero de cualquier forma, más allá de sus propósitos, es notorio que el anónimo autor no se contentó con establecer una relación de causa a efecto entre las confrontaciones fratricidas de los partidos visigodos y lo que él presenta como una gran "iniquidad" 15 , sino que insiste haciendo de ellas la clave argumental de su discurso.

Las mismas pautas rigen el texto de la versión "a Sebastián", salvo que su autor, aunque no reitere en la culpabilidad de los parientes de Vitiza, amplía su responsabilidad, acusándoles de haber enviado mensajeros a África con expresa solicitud de ayuda para sus planes contra Rodrigo, además de "meterlos" literalmente en España, tras facilitarles el viaje mediante el envío de barcos ${ }^{16}$. Por último, recordemos que a juicio del autor de la Crónica albeldense, serán los enredos de los godos y más concretamente de los hijos de Vitiza, los causantes de la irrupción musulmana ${ }^{17}$.

Y esa idea será, igualmente, la que emane de las crónicas musulmanas: la intervención de las tropas de Tariq contó con el aliento y ayuda de destacados personajes del mundo visigodo.

Según el Ajbar Machmua, colaboracionista, desde la primera hora fue el conde Don Julián. Se trata, ciertamente, de un personaje con ribetes de leyenda, que ha dado lugar a toda suerte de especulaciones relacionadas con su origen y el espacio territorial sobre el que ejercía su autoridad. Pero sobre el que los variados relatos que poseemos parecen coincidir en lo que se refiere a su profesión de la religión católica, a su radicación en el norte de África y a las razones de orden personal que motivaron su vinculación a la causa islámica ${ }^{18}$. Por lo demás los interrogantes se multiplican respecto a su trayectoria política anterior a sus compromisos con Muza ${ }^{19}$, pero esta cuestión no afecta al análisis que vengo haciendo. Como tampoco afecta la excusa del honor mancillado en la persona de su hija Florinda (o la Caba); una excusa aducida en la mayor parte de las fuentes y recogida en un elenco amplísimo de creaciones literarias basadas en la figura de susodicha hija ${ }^{20}$.

\section{${ }^{14}$ Rotense, 7}

${ }^{15}$ Una iniquidad mayor que las anteriores: Cuius tempore adhuc in peiori nequitia cr euit Spania. Rotense, 7, p. 120.

16 "a Sebastián”, 6. El texto latino dice: “...callide cogitantes missos ad Africam mittunt, Sarracenoos in auxilium petunt eosque nauibus aduectos Yspaniam intro mittunt". J. L. MoraleJo, traduce: "con artero designio mandan emisarios a África, piden ayuda a los sarracenos y, una vez que pasaron a bordo de naves, los meten en España."

17 "A causa de los hijos de Vitiza surge entre los godos un enfrentamiento que da lugar a disputas, de manera que una parte de ellos ansiaba ver el reino destruido.; incluso por favor y enredo de ellos, entraron los sarracenos en España" (Crónica albeldense XVII, 1).

${ }_{18}$ Ajbar Machmuâ, ed. de E. Lafuente Alcantara, Madrid, 1987, pp. 18 y ss. Véase también, P. Chalmeta, Invasión e islamización, Madrid, 1994, pp. 113-115.

19 Pues primero Julián tuvo que enfrentarse al propio Muza que deseaba conquistar las ciudades costeras y luego hacer frente, con las armas en la mano, a los ataques que Muça organizaba contra él desde Tánger. Ajbar Machmuâ, pp. 18 y ss.

${ }^{20}$ Con referencia a esta cuestión de enorme proyección literaria, pero escasa credibilidad histórica, véanse las páginas que le dedica P. Chalmeta (Invasión e islamización, pp. 119-121), donde concluye que el rey Rodrigo no disponía de tiempo material para violentar a la Caba. 
Lo que nos importa es que en un momento dado, por razones no bien determinadas ${ }^{21}$, Julián además de recomendar al musulmán la conquista de España, se puso a su servicio para facilitar el proyecto. De la trascendencia de su ayuda da buena cuenta el Ajbar Machmûa, que le atribuye, primero una descripción de España, junto con la exhortación a Muza de programar su conquista ${ }^{22}$ y luego, tras el desembarco, lo que aún fue más decisivo: el ofrecimiento de expertos que guiaran y orientaran a los ejércitos islámicos por los caminos de España ${ }^{23}$.

De modo que, si para las fuentes islámicas la quintaesencia de la colaboración estuvo representada por Julián y sus adláteres, para las cristianas por los parientes de Witiza, destacando de entre ellos en el segundo período, el de la conquista, el obispo Oppas.

Cabría preguntarse por las razones de esas diferencias en cuanto a la personificación de un modelo de comportamiento que debió ser bastante común. Yo me atrevería a decir que los musulmanes pusieron el acento en la importancia de sus aliados de la primera hora y los cristianos valoraron muy en concreto los daños provocados en su causa por un amplio sector de la nobleza visigoda en el que militaban incluso jerarquías eclesiásticas. Porque, en definitiva, sobre ellos se arrojaba toda la responsabilidad de esa desguarnición moral de España a la que vengo aludiendo.

Además, conviene recordar que, desde luego, colaboracionistas en los procesos de conquista fueron muchas comunidades judías. A ellas se les encomendó la guarda de ciudades tan emblemáticas y estratégicas como eran las de Granada ${ }^{24}$, Córdoba $^{25}$ y Sevilla ${ }^{26}$. No fue ese el caso de Málaga, porque allí las tropas del Islam no encontraron pobladores de ningún credo religioso. Este dato permite afirmar que tampoco el comportamiento de las comunidades judías se atuvo a un patrón homogéneo.

21 P. Chalmeta, Invasión e islamización, pp. 118-119. Cabe recordar, por lo que se refiere a la causa más conocida, la que tiene más eco en el literatura, la que tiene como justificación la violencia sexual del rey Rodrigo sobre la hija de Julián. Se trataba de un argumento para uso de los arabo-musulmanes (p. 120)

22 “(Julián) Mandó enseguida su sumisión a Muça, conferenció con él, le entregó las ciudades puestas bajo su mando en virtud de un pacto que concertó con ventajosas y seguras condiciones para sí y sus compañeros y habiéndole hecho una descripción de España, le estimuló a que procurase su conquista." Ajbar Machmûa, p. 20.

${ }^{23}$ La crónica sitúa el episodio tras la batalla de Écija, momento en el que Julián se dirige a Tarik con el siguiente discurso: "Ya has concluido con España: divide ahora tu ejército, al cual servirán de guías estos compañeros míos, y marcha tu hacia Toledo." (Ajbar Machmûa, p. 23). Más expresivo es el texto de AL-MAKKARI, (ed. de E. LAFUENTE ALACÁNTARA, Apéndice de la ed. del Ajbar Machmûa Madrid, 1867, p. 177), en donde se cuenta como en las fechas previas a la batalla del Guadalete, Muza mandó a Tarik tropas de refuerzo en las que se alistaba Julián, con sus propios soldados y gentes de la provincia a su mando, "que indicaban a los musulmanes los puntos más vulnerables y les servían de espías."

24 Ajbar Machmua, p. 25: " los musulmanes tomaron la capital de Elvira, Granada y como en ella encontraron a muchos judíos, comenzaron, a lo que parece se convirtió en una tradición que consistió en encomendar las ciudades que iban controlando a destacamentos musulmanes junto a las comunidades de judíos.".

${ }^{25}$ Ajbar Machmûa, p. 27: "Reunió en Córdoba a los judíos a quienes encomendó la guarda de la ciudad, distribuyó en ella a sus soldados y se aposentó él en el palacio."

${ }^{26}$ Ajbar Machmûa, p. 28: "Confió Muça la guarda de la ciudad a los judíos”. 


\section{LA DERROTA DEL EJÉRCITO VISIGODO: SUS CONSECUENCIAS}

Parece desprenderse, tanto de las fuentes cristianas como de las musulmanas, que el rey Rodrigo se había hecho acompañar por la práctica totalidad de su ejército en la marcha hacia el $\operatorname{sur}^{27}$. Y queda igualmente confirmado que el rey y los miembros del ejército que le eran leales no sólo sufrieron una afrentosa derrota de manos de sus enemigos, sino que de hecho, perdieron la mayor parte de sus capacidades operativas. El rey porque que la batalla significó su final -al menos político, muy probablemente también físico ${ }^{28}$. Los leales al caudillaje de Rodrigo, porque o bien perecieron en la batalla de Guadalete ${ }^{29}$, o bien fueron dispersados en la persecución que sucedió a la derrota ${ }^{30}$. De modo que la primera consecuencia de la derrota fue el colapso de las estructuras militares, que quedaron diezmadas y descabezadas. Porque fueran quienes fuesen los responsables del fracaso, todas las fuentes tempranas parecen estar de acuerdo en que las consecuencias de la misma se produjeron de forma inmediata y consistieron en la aniquilación, ya en el campo de la contienda ya

${ }^{27}$ La Crónica del 754 notifica que el rey Rodrigo reunió "un gran ejército contra los árabes y los moros enviados por Muza" (52, p. 69). Siglos después, las crónicas asturianas abundan en estas ideas. Pues, aunque la Rotense (7, p. 200) sólo diga que Rodrigo "salió con el ejército para luchar" contra los musulmanes, el autor de la "a Sebastián" $(6, p .201)$ enfatiza el relato al escribir que el rey salió al paso de los sarracenos "con todo el ejército de los godos". El Ajbar Machmûa, (Ed. Emilio Lafuente Ferrari, Madrid, 1867) no sólo pondera el volumen de ese ejército que cifra en torno a 100.000 hombres (p. 21), sino su peso cualitativo (al decir de su autor en él se alistaba "la flor de la nobleza española y los hijos de sus reyes", p. 21). Aún añade más en párrafos posteriores: que si ese ejército no contaba con más efectivos era debido a la mortandad ocasionada por la peste de los años inmediatamente anteriores: "Aproximose, pues, con un ejército de cerca de 100.000 combatientes, y tenía este número (y no otro mayor) porque había habido en España un hambre... (p. 22).

${ }_{28}$ De la muerte del rey en el campo de batalla habla la Crónica mozárabe (52, p. 68) y lo hace con el verbo cecidit que no deja opción a la duda. El Ajbar Machmua, pp. 22-23 informa al respecto, de que "Rodrigo desapareció, sin que se supiese lo que le había acontecido, pues los musulmanes encontraron solamente su caballo blanco, con su silla de oro, guarnecida de rubíes y esmeraldas y un manto tejido de oro y bordado de perlas y rubíes... Sólo Dios sabe lo que le pasó, pues no se tuvo noticia de él ni se le encontró vivo ni muerto." Las mismas dudas sobre el destino del último rey visigodo encontramos en las crónicas alfonsinas, donde tanto la versión rotense como la de "a Sebastián", afirman no saber nada cierto respecto de su muerte. Pero añaden un dato de subido valor por lo que respecta a las pretensiones de veracidad que mueven a los autores de ambos textos, que en su tiempos (los del rey Alfonso III), se ha descubierto en una basílica de Viseo un sepulcro cubierto con una lápida a nombre de "Rodrigo, último rey de los godos" (Rotense, 7, pp. 200-201). También hay una mención al sepulcro de Rodrigo en "a Sebastián", 7.

${ }^{29}$ El Ajbar Machmûa, p. 23, afirma tajantemente que, tras la deserción de los hijos de Witiza: "los musulmanes hicieron una gran matanza en los enemigos". Las crónicas asturianas recogen esas ideas: La rotense (7, p. 200) afirma que "puesto en fuga el ejército, fue destruido hasta el exterminio." Similar apreciación encontramos en "a Sebastián" (7, p. 201): "todos los ejércitos de los godos se dieron a la fuga y fueron exterminados por la espada."

${ }^{30}$ El Ajbar Machmûa, hace confluir a los vencidos en Écija. Fue ante sus muros donde, según esta fuente, el ejército visigodo volvió a plantar cara, de forma conjunta, a los musulmanes. A partir de ahí, éstos "no volvieron a encontrar tan fuerte resistencia." (p. 23). Por el contrario, a partir de aquella experiencia: "huyendo hacia Toledo, se encerraron en las ciudades de España (p. 23). 
en sus inmediaciones, de buena parte del ejército visigodo ${ }^{31}$. De modo que no extraña que, tras el choque y las matanzas que se sucedieron, la España visigoda quedase descabezada y en situación de total indefensión militar.

Situación que siendo de por sí comprometida, se vio agravada por el estado de desconcierto en que quedaron las élites de los derrotados y, con ellos, gran parte de la población de Hispania.

Desde estas perspectivas nosotros estamos autorizados a admitir -con el autor de la crónica del 754 y con sus deudores, los historiadores asturianos-, que la España tradicional, la España ya aceptablemente cristianizada y aparentemente unificada por los visigodos "se perdiera" en el Guadalete, al quedar totalmente desguarnecida, tanto militar como ideológicamente.

Por lo que se refiere a la crisis ideológica, baste recordar que no sólo el desembarco y la inmediata batalla campal se produjeron en el seno de una confrontación interna, también los acontecimientos subsiguientes estuvieron marcados por el signo de la misma. Especial significación cobran en este contexto las acusaciones vertidas por las fuentes cristianas sobre el inclemente proceder de sus correligionarios durante el curso de las operaciones de conquista. Entre ellos el autor de la Crónica mozárabe, destaca el protagonismo de Oppas, "el hijo de Witiza", con cuya colaboración, Muza condena al patíbulo y mata con la espada, a seniores nobiles viros, que aún quedaban en la ciudad de Toledo, tras la desbandada general de su población ${ }^{32}$.

De modo que podemos afirmar que la desguarnición ideológica, lejos de morir o atemperarse con la derrota, experimentó, si cabe, un incremento de sus síntomas. Y que ella unida a la castrense contribuyó a acentuar el clima de desconcierto que, a lo que dicen las fuentes, caracterizó aquel tiempo histórico en las sociedades cristianas.

No extraña, pues, que el desconcierto de los primeros meses fuera inenarrable, aunque sólo hayan llegado del mismo unos ecos difusos. Un desconcierto que intuimos motivado, desde luego, por el descabezamiento de los rodriguistas y la falta de capacidad operativa del ejército visigodo puesta de manifiesto en Écija ${ }^{33}$ y en el avance incontenible de las tropas aliadas hacia Toledo y Zaragoza. Pero también por la opacidad del proyecto político vitizano - una opacidad que sigue inquietándonos hasta hoy mismo- y las incógnitas acumuladas en torno al papel que se reservaban los desembarcados. Parece que muy pocos supieron del alcance de los pactos que los extranjeros habían firmado con los enemigos de Rodrigo y menos aún serían los que

${ }^{31}$ En "a Sebastián", 7 se lee: "todos los ejércitos de los godos se dieron a la fuga y fueron aniquilados por la espada". En un párrafo anterior (6), el mismo autor, ampliando las noticias sobre la petición de ayuda cursada por los vitizanos a los musulmanes y en la línea moralizante que le caracteriza, revela que quienes "introdujeron en la patria la perdición, perecieron junto con su gente por la espada de los sarracenos. Por su parte el autor de la rótense, 7 escribe: "Puesto en fuga, el ejército fue destruido hasta casi el exterminio."

${ }^{32}$ Crónica mozárabe, 54.

33 Ajbar Machmuâ, p. 23: En Écija, donde se concentraron los "fugitivos del ejército grande", se trabó una batalla que costó a los musulmanes muchos muertos y heridos, pero de la que al fin salieron victoriosos. "Dios les concedió al fin su ayuda" y ya no volvieron a encontrar tan fuerte resistencia. 
tuvieron noticia de las ambiciones de los desembarcados. También es probable que de los proyectos inmediatos de los musulmanes no supieran ni ellos mismos ${ }^{34}$.

Es cierto que, inscrito el desastre en las coordenadas propias de la tradición visigoda, nada de esto tendría porque sorprender, al menos, a las familias aristocráticas acostumbradas a capear esos temporales. Pero si las matanzas se cebaron con los rodriguistas en el grado que dicen las fuentes, no cabe duda que el partido quedaría totalmente fragmentado y sin posibilidades de maniobra. De modo que los derrotados, incapaces de aunar esfuerzos, no pudieron formalizar un frente común en el que se alistaran los neutrales, sin duda la mayor parte de la población. Es de suponer que el hecho de que en el bando vencedor figuraran personalidades visigodas, destacadas tanto en la esfera político-militar como en la religiosa, contribuiría a enturbiar la situación.

Se explicarían así los intentos descoordinados de resistencia de que nos hablan las fuentes ${ }^{35}$, los sucesivos descalabros militares, las búsquedas de soluciones particulares, entre las que se citan las primeras huidas de los naturales hacia áreas montañosas del territorio hispano ${ }^{36} \mathrm{o}$ la aceptación del sistema de pactos ofrecido por los musulmanes.

A esos enigmas respecto del proceder futuro de los desembarcados se alude en el Ajbar Machmua, en varias ocasiones, la primera cuando el cronista atribuye a las facciones del ejército visigodo que planeaban desertar de las filas rodriguistas, la identificación de sus advenedizos aliados con destacamentos de mercenarios tan sólo interesados por el botín y deseosos, en consecuencia, de retornar a la tierra de la que procedían, una vez conseguidos sus objetivos ${ }^{37}$. Luego, en páginas posteriores, al recordar los sentimientos de gratitud de los musulmanes a su Dios por el terror que había infundido en los corazones de tantos cristianos cuando "vieron que Tarik se internaba en el país, habiendo creído que haría lo mismo que Tarif" ${ }^{38}$.

Ello, unido al hecho de que por estos meses se multiplicaran los desastres militares y los fracasos en el intento de resistencia explica la generalización del recurso a los pactos. El caso paradigmático es el del godo Teodomiro, al que el Ajbar Machmûa, pondera por el gran ingenio que demostró en las negociaciones. Pero de todo

${ }^{34}$ Como afirma Pedro CHALMETA (Invasión e islamización, p. 121) las fuentes árabes no dan la idea de estar describiendo una acción de envergadura, oficial, preparada y programada, sino más bien acciones inconexas resultado de una serie de iniciativas individuales.

${ }^{35}$ El Ajbar Machmûa, se refiere a las resistencias que opusieron ciudades como Córdoba donde el grueso de la guarnición no pasaba de 500 hombres, Granada y Toledo (pp. 23-24).

${ }^{36}$ Ajbar Machmûa, (p.25) afirma que conquistada Rayya, "sus habitantes huyeron a lo más elevado de los montes."

${ }^{37}$ El texto, sumamente expresivo, informa de una conferencia en el campo de batalla de los enemigos de Rodrigo en la que se propala la siguiente información: "Este hijo de mala madre (Rodrigo) se ha hecho dueño de nuestro reino sin ser de estirpe real, antes bien, uno de nuestros inferiores: aquella gente no pretende establecerse en nuestro país; lo único que desean es ganar botín: conseguido esto se marcharán y nos dejarán.” (p. 21).

${ }^{38}$ Ajbar Machmûa, p. 23. En páginas anteriores (p. 20) la misma fuente había relatado la incursión de Tarif, al frente de 400 hombres, 100 de ellos de caballería. Protagonizó una algara contra Algeciras y volvió a África "sano y salvo" con tantos cautivos como "ni Muça ni sus compañeros los habían visto semejantes" y un abultado botín. 
cuanto dice la crónica lo único que a mi me interesa es la secuencia de los acontecimientos: el caudillo visigodo, tras fracasar en su intento de detener a los musulmanes en campo abierto y perder la práctica totalidad del ejército en el combate, urdió el engaño que le permitió negociar con los musulmanes una paz, en condiciones ventajosas $^{39}$. Y aunque, ciertamente las condiciones no eran desfavorables a la población cristiana, al significar la total renuncia al uso de la armas y la actividad militar, implicaban, en definitiva el sometimiento a la voluntad de los desembarcados y la aceptación de su soberanía. En otros términos, representaba la conversión de los firmantes en tributarios del Islam $^{40}$. De modo que Teodomiro no es sino el ejemplo vivo de ese proceso de implantación musulmana que la Crónica mozárabe resume en una sola frase: “...sembrando en todos el pánico, las pocas ciudades restantes se ven obligadas a pedir la paz, e inmediatamente, complacientes y sonriendo, con cierta astucia, conceden las condiciones pedidas" 41 .

Una segunda expedición musulmana al año siguiente de la de Tariq y las experiencias cosechadas en las relaciones con los desembarcados fueron clarificando el panorama y orientando la política de los hispanos en el único sentido que parecía garantizarles la supervivencia: aceptar las paces propuestas por los vencedores.

En efecto; en el mes de ramadán del año 712 pisaba suelo peninsular Muça, el gobernador de Africa, y lo hacía, según el testimonio de Ajbar Machmûa, acaudillando un ejército de 18.000 hombres $^{42}$. Inmediatamente inició un camino de progresión hacia el norte, completando la lista de plazas que pasaban a integrarse en el dominio islámico. Las noticias del desembarco y de la actuación del caudillo musulmán tuvieron que expandirse por todos los rincones de Hispania. Medina Sidonia fue conquistada ${ }^{43} \mathrm{y}$ aunque la fortaleza de Carmona requirió del empleo de una estratagema de poco aliento épico, al cabo, también fue rendida ${ }^{44}$. Sevilla y Mérida necesitaron meses de asedio, pero faltas de ayuda exterior tuvieron que entregarse. La última, que presentó una brava y contumaz resistencia, cayó en poder de los invasores el mes de ramadán del $713^{45}$.

${ }^{39}$ El engaño consistió en colocar mujeres en las murallas, simulando una guarnición de la que ya no disponía la plaza (Ajbar Machmûa, p. 26).

40 Así lo entiende la Crónica Mozárabe, 51, para cuyo autor el reino godo, tras 350 años de Historia, fue destruido y hecho tributario por obra del ejército islámico capitaneado por Muza.

${ }^{41}$ Crónica mozárabe, 54.

${ }^{42}$ Muça desembarcó en España el mes de Ramadán del año siguiente con 18.000 hombres Ajbar Machmua, p. 28.

${ }^{43}$ Ajbar Machmûa asegura que Muza la "conquistó por fuerza de armas" p. 28

${ }^{44}$ Ajbar Machmûa, p. 28 cuenta que cuando el caudillo musulmán estuvo frente a la ciudad se dio cuenta de que nodía conquistarla ni por asalto ni por asedio. Anónimos asesores le dijeron que sólo se podría hacer con ella mediante una estratagema. Entonces mandó a algunos cristianos de los que habían pedido y obtenido de él carta de seguridad, como Julián, de quien acaso eran camaradas, y se presentaron armados, como si fuesen fugitivos, siendo recibidos en la ciudad; mas por la noche abrieron la puerta llamada de Córdoba a la caballería que Muça mandó al intento, y sorprendiendo a la guardia, se apoderaron los musulmanes de Carmona."

${ }^{45}$ Ajbar Machmûa, p. 29. Muça encontró en Mérida la mayor resistencia. La fortaleza de su arquitectura militar le obligó a emplear sistemas poliorcéticos avanzados, como fue "fabricar una máquina para acercarse al muro". De todas formas, la resistencia de la ciudad se alargó pues los defensores atacaron a 
Paralelamente a estos acontecimientos, el trato inmisericorde que los caudillos expedicionarios aplicaron a cuantos osaron resistir empuñando las armas, fue surtiendo sus efectos, de modo que los hispanos se vieron ante el dilema de aceptar las paces propuestas por los musulmanes o mantener una confrontación armada que, en ningún caso, se vio coronada por un éxito duradero ${ }^{46}$. Es cierto que podían también buscar refugio en zonas marginales, pero el número de las mismas era cada vez más reducido por cuanto los musulmanes aumentaban a ritmo vertiginoso la superficie geográfica que controlaban.

\section{LA RECUPERACIÓN DE LA CONCIENCIA DE IDENTIDAD Y SUS SOPORTES}

Ahora bien, durante los meses de forzadas relaciones, los cristianos tuvieron ocasión de conocer, por experiencia directa los modelos de comportamiento, las fórmulas sociales y los esquemas morales de sus huéspedes. Y no parece que del conocimiento se derivara un aprecio sincero. Al menos eso se desprende de la lectura del conocido párrafo de la Crónica Mozárabe en el que su autor narra la segunda huida de los cristianos a los refugios montañosos, tras denunciar los pactos acordados con los advenedizos. Dice el anónimo cronista que llenos de temor, aquellos que habían aceptado pactar, se niegan a acatar los acuerdos antes solicitados y huyen a las montañas donde perecen por hambre y otras causas ${ }^{47}$.

Pero las crónicas cristianas no son las únicas en acumular datos sobre la insensibilidad de los recién llegados. Más precisas si cabe, en esta materia son las musulmanas. A ellas debemos los datos más significativos respecto de unas conductas tan inmisericordes en demasiadas ocasiones, que mueve a pensar en la utilización sistemática de métodos de terror.

En el registro de comportamientos violentos anotamos métodos tales como la consideración del cautivo como prenda personal y la ejecución sistemática de los prisioneros. Un caso de agresión inmisericorde es la que sufre el gobernador godo de Córdoba asesinado, a sangre fría, por el conquistador de la ciudad, el liberto Mugith al-Rumi ${ }^{48}$ con el pretexto de que él lo había hecho prisionero y él disponía de su vida ${ }^{49}$. Y si el maltrato a los prisioneros está documentado, también lo están las sangrías que causaron las operaciones musulmanas entre los combatientes cristianos. Ya he hecho alusión a la matanza que siguió a la derrota del Guadalete ${ }^{50}$, pero, ade-

los asaltantes que socavaban el muro de argamasa de una de las torres provocando una matanza. Los muertos alcanzaron la consideración de mártires, dando nombre así a una de las torres de la fortaleza islámica

${ }^{46}$ El pacto del que habla Ajbar Machmûa, p. 30, firmado con Mérida es todo un ejemplo. "Ajustaron, en efecto, la paz, a condición de que los hispanos contratantes se quedaran con sus bienes, los vencedores con los de los combatientes fallecidos en la emboscada que les tendió Muça y los huidos a Galicia y el propio Muça con los "bienes y las alhajas de las iglesias".

47 "Sed ubi inpetrata territi metu recalcitrant, ad montana temti iterum effugientes fame et diuersa norte periclitant" (Crónica mozárabe, 55).

48 Sobre la campaña de Córdoba véase P. Chalmeta, Invasión e islamización, pp. 151 y ss.

49 Ajbar Machmûa, p. 31. En su disputa con Muza que reclama al prisionero Mugith dice: "Yo le aprendí y le cortaré la cabeza"

50 Véase la nota.29.. 
más, sabemos de otras como las que se produjeron entre los miembros del ejército de Tudmir ${ }^{51}$. Aunque, sin duda el episodio más significativo se registró en Córdoba donde Mugith, su conquistador no tuvo reparos en pasar por la espada un contingente de entre 400 y 500 hombres que se habían refugiado en una iglesia donde se hicieron fuertes y trataron de resistir ${ }^{52}$. También Muça logró masacrar a los sevillanos en campo abierto tras tenderle una emboscada. El Ajbar Machmûa, asegura que la matanza fue grande, pero lo cierto es que los supervivientes lograron defender la ciudad durante meses ${ }^{53}$.

De modo que los cristianos tenían sobradas razones para experimentar ese terror que tantas veces les llevó a admitir las condiciones de paz impuestas por los musulmanes. Ahora bien lo que sorprende y desconcierta es la naturaleza de ese miedo del que nos habla el cronista mozárabe, un miedo producto de la concertación de un acuerdo que garantizaba al menos la vida. ¿De qué miedo se trata? Desde mi óptica personal sólo cabe una respuesta, es un miedo consecuente al sentimiento de la pérdida de identidad.

En cualquier caso, de lo que no cabe duda alguna es de que la aceptación de los pactos suponía la renuncia a la defensa mediante el ejercicio de las armas. O dicho en otros términos que son los que interesan al tema que trato, los pactos supusieron la dejación por parte de la población vencida del ejercicio de las armas. Así lo entendieron los cronistas asturianos que pondrán el acento en las graves consecuencias que podían derivarse de unos acuerdos que suponían la indefensión radical ${ }^{54}$. Y esa renuncia a la defensa armada por parte de los hispanos, era, indiscutiblemente y en sentido inverso, uno de los argumentos más sólidos, de los nuevos dominadores respecto a los derechos patrimoniales que iban adquiriendo sobre las tierras en las que se estaban aposentando. Se trataba de una conquista particular, lograda por su esfuerzo militar ${ }^{55}$, sancionada por su habilidad diplomática y bendecida por su Dios $^{56}$.

${ }^{51}$ Ajbar Machmûa, p. 26, la matanza fue tal que "que casi los exterminaron".

52 Ajbar Machmûa, p. 25. Era la iglesia de San Acisclo, situada en la parte occidental de la ciudad, la fortaleza de la iglesia y la solidez de sus muros permitió que la defensa se prologara durante tres meses. Hasta que pudo escapar el gobernador de la ciudad a uña de caballo, camino de Toledo. Moguits, tras alcanzar al huido, volvió a la ciudad, "hizo salir a todos los cristianos y mandó se les cortase la cabeza" (p. 27). No deja de ser llamativo el nombre que recibió la iglesia: "iglesia de los prisioneros".

${ }^{53}$ p. 29.

${ }^{54}$ Así lo entendió el autor de la Crónica albeldense. XVII 3b: Tras siete años de guerra se comprometieron a un pacto y tomaron el acuerdo de desmantelar las ciudades, habitar aldeas, elegir condes que pagaran los tributos debidos al rey y así "ellos son siervos adquiridos por medio de las armas".

${ }^{55}$ Un esfuerzo que se había logrado no pocas veces con el sacrificio propio Ajbar Machmûa (p. 29) la conquista de Mérida.

${ }^{56}$ Ajbar Machmûa multiplica las referencias al respecto. Porque su autor atribuye la decisiva batalla de Écija, a partir de la cual se diluyó la resistencia hispana, a la ayuda divina: "sus habitantes (los de Écija), acompañados de los fugitivos del ejército grande, saliéronle al encuentro, y se trabó un tenaz combate, en que los musulmanes tuvieron muchos muertos y heridos. Dios les concedió al fin su ayuda y los politeístas fueron derrotados". (p. 23). Fue también su Dios el que, a su juicio, sembró el terror "en los corazones de los cristianos" cuando vieron que Tarik se internaba en su tierra. (p. 23). También agradece a Dios el aguacero y la granizada caída la noche oscura que los musulmanes se hicieron con 
En este panorama cobra sentido y valor testimonial la personalidad entre épica y profética de don Pelayo. Porque él es el ideólogo de un proyecto de "salvación de España" y su primer gestor. A su visión profética se debe, al decir de las fuentes asturianas, el diseño del nuevo régimen cristiano construido sobre dos instituciones fundamentales: la iglesia de Dios y el ejército de los godos

Porque para la cronística asturiana Pelayo es la encarnación misma del rebelde que ha denunciado los pactos y se ha alzado contra el dominio musulmán. Él es la encarnación de los grupos de hispanos que, tras comprobar, colectiva y personalmente, las consecuencias de los acuerdos pactados y el alcance de la sumisión aceptada, rompen los acuerdos, se declaran en rebeldía, y tratan de escapar del control musulmán. Es en este momento, cuando las áreas montañosas de la península van a jugar un papel decisivo como zonas de refugio ${ }^{57}$.

Ahora bien más allá de esa identificación genérica, las notas biográficas que le atribuyen las distintas fuentes que componen la antedicha colección cronística difieren de forma tan sensible que en ciertos pormenores llegan a la contradicción flagrante. Yo me atendré a la versión de la Crónica Rotense, por ser la más larga y coherente desde los presupuestos militares -que son los que a mi estudio interesan-, evitando entrar en cuestiones genealógicas o litigios a cerca del carácter del caudillaje que al personaje le tocó ejercer ${ }^{58}$.

Según su autor, Pelayo, antiguo "espatario" de los reyes Vitiza y Rodrigo, llegó a Asturias, junto con su hermana, "agobiado por la dominación de los ismaelitas". (Rot. 8). No obstante esa malquerencia y por causa que desconocemos, desde Gijón fue comisionado a Córdoba por Munnuza, el gobernador musulmán de la zona. Bien conocido es el hecho de que al regreso encontró a su hermana casada con el gobernador y que fue tal su disgusto que "se aprestó a poner en práctica lo que ya tenía pensado en torno a la salvación de la Iglesia." A partir de ese momento el militar godo se verá en la necesidad de sortear la persecución de la maquinaria represora musulmana. Y si logró salir con bien de la empresa fue gracias a que los astures aceptaron por una parte sus propuestas de constituirse "bajo el amparo de las montañas" en comunidad insurrecta y, por otra, su caudillaje frente a las previsibles represalias musulmanas.

De modo que Pelayo pudo hacer frente a la hueste "innumerable" mandada contra él desde Córdoba porque contó con la colaboración de sus camaradas-cum sociis suis, dice el cronista ${ }^{59}$. Pudiera caber dudas acerca de quiénes eran estos socios con los que el godo se aprestaba a la resistencia, pero como ya he dicho, en el capítulo anterior, el cronista ha dejado claro que Pelayo era el caudillo de los astures, en la jornada de Covadonga. Y lo es, porque se ha promovido él así mismo, en un proceso que a más de dilatado parece muy acorde con el tiempo histórico y las realidades geográficas. Un proceso en dos tiempos, el primero en el que se presenta ante un "consilium"

la plaza fuerte de Córdoba: "Llegada la noche se acercó Moguits, y favoreciendo Dios su empresa con un aguacero, mezclado con granizo...” (p. 24).

${ }^{57}$ Pelayo fue el primero "que se metió en las ásperas montañas, bajo la peña y cueva de Auseva" (Crónica Albeldense, XVa, 1).

${ }^{58}$ Sobre el personaje véase, A. BesGa, Orígenes hispano-godos del reino de Asturias, pp. 191 y ss.

${ }^{59}$ Rotense. 9, p. 124. 
de astures, el segundo en el que reunidos los astures le "eligen como su príncipe" También la Crónica Albeldense parece corroborar el relato anterior, al afirmar que Pelayo fue el primero en rebelarse en Asturias en un tiempo en el que Munuza, en la ciudad de Gijón, "cumplía las órdenes de los sarracenos sobre los astures"

No obstante, conviene recordar que la crónica "a Sebastián" hace de Pelayo y los suyos, visigodos de linaje real ${ }^{62}$. Pero aunque así fuera, parece difícil que un grupo de godos huidos, por muy selecto que fuera, pudiera haber prescindido de la colaboración de los naturales del país para una operación que se preveía larga y erizada de dificultades.

En definitiva podemos concluir que en las últimas décadas del siglo Ix, la memoria colectiva de los cristianos del norte guardaba el recuerdo de un tiempo decisivo en el que un movimiento con bastantes ribetes de espontaneidad, cambió el signo de su Historia. Según esa memoria, aquella inflexión se produjo cuando los naturales del país, decidieron aprovechar el saber militar de un antiguo portaestandarte para rebelarse, una vez más, contra un poder centralizador radicado en el sur de la Península.

Y, a tenor de la información que trasmiten la rotense y la albeldense, podemos afirmar que el contingente que resiste la presión de los musulmanes está integrado, en su mayoría, por nativos. Se trataría, pues, de un ejército de signo popular, aunque contara con la presencia de godos e hispanos alzados y algún que otro noble huido o establecido en la zona desde atrás.

Pero hay más; porque en el curso de los enfrentamientos entre musulmanes y cristianos - esos que conocemos como batalla de Covadonga- Pelayo, encarándose dialécticamente con el obispo Oppas, pronuncia una alocución que es, además de un alegato religioso, un programa de futuro. Alegato religioso porque el rebelde manifiesta públicamente su fe en Cristo, al que ha escogido por abogado. Programa de futuro, porque expresa su inquebrantable decisión de resistir con las armas en la mano en la confianza de que gracias a esa mediación se restaure: "la salvación de España y el ejército del pueblo godo"63. Por lo que no hay duda de que tanto en la memoria colectiva como en la propaganda oficial, quedará la idea de que este episodio bélico que marcó el inicio de un largo proceso, propició, asimismo, el arranque de la restauración del ejército visigodo ${ }^{64}$.

En definitiva; en el relato que el autor de la Crónica Rotense hace de la batalla de Covadonga se encuentran los fermentos mismos de la reordenación militar que

${ }^{60}$ rot. 8 , p. 124 y 202.

${ }^{61}$ Crónica Albeldense, $X V$.

${ }^{62}$ En efecto, de las contadas referencias que el autor de "a Sebastián" hace a los seguidores de Pelayo, cabe deducir que se trata de gente goda, más aún, representantes de la alta nobleza visigoda. Así, tras narrar la caída de la monarquía visigoda, el cronista escribe: "Mas los godos perecieron parte por la espada, parte por el hambre. Pero los que quedaron de estirpe regia, algunos de ellos se dirigieron a Francia, pero la mayor parte se metieron en la tierra de los asturianos, y a Pelayo, hijo del antaño duque Fávila, de linaje real lo eligieron por su príncipe" $(<\mathrm{a}$ Sebastián, $8>$ ).

${ }^{63}$ Rotense, 9. "Spes nostra Xps est quod per istum modicum monticulum quem conspicis sit Spanie salus et Gotorum gentis exercitus reparatus."

${ }^{64}$ Recuérdese que así se lo anuncia Pelayo al obispo Oppas cuando afirma que por aquel monte y gracias a Cristo se va a restaurar "la salvación de España y el ejército del pueblo godo". (Rotense. 9). 
requería un proyecto de sociedad cristiana independiente. Una reordenación basada en principios éticos - la leal colaboración de los afectados en la defensa de la tierra-y la aplicación de los saberes militares que habían procurado tantas victorias a los visigodos - los saberes de los que disponía el espatario Pelayo-. Porque de la institución militar, dependía, primero en el intento de resistencia y luego, cuando las circunstancias lo fueron permitiendo, en un proyecto restaurador de mayor envergadura ${ }^{65}$.

${ }^{65}$ Proyecto en el que se encuentran comprometidos los cristianos de finales del siglo ix que "día y noche afrontan la batalla y cotidianamente luchan pero no logran quitarles España del todo". (Crónica Albeldense, XIV, 34). Sobre la organización del ejército M. Torres Sevilla, "La España del Norte (Siglos VIII a XI) en Historia militar de España. Edad Media. Madrid, 2010, pp. 109 y ss. 